\title{
Failure of retrograde cerebral perfusion to attenuate metabolic changes associated with hypothermic circulatory arrest
}

\author{
R. S. Bonser, FRCP, FRCS ${ }^{a}$ \\ C. H. Wong, MA, FRCS \\ D. Harrington, MRCS ${ }^{a}$ \\ D. Pagano, MD, FRCS \\ M. Wilkes, FRCA ${ }^{\text {b }}$ \\ T. Clutton-Brock, MRCP, FRCA ${ }^{\mathrm{b}}$ \\ M. Faroqui, FRCA ${ }^{b}$
}

From the Cardiothoracic Surgical Unit ${ }^{\mathrm{a}}$ and Department of Anaesthesia and Intensive Care, ${ }^{b}$ University Hospital Birmingham Queen Elizabeth Medical Centre, Birmingham, United Kingdom.

This work was supported by the Kate Weeks Research Fellowship of the Royal College of Surgeons of England.

These data were presented in part at the American Heart Association Scientific Sessions, Atlanta, November 1999.

Received for publication Oct 11, 2000; revisions requested Feb 5, 2001; revisions received Aug 1, 2001; accepted for publication Sept 18, 2001.

Address for reprints: Robert S. Bonser, FRCS, MRCP, Cardiothoracic Surgical Unit, Queen Elizabeth Hospital, Edgbaston, Birmingham, B15 2TH, United Kingdom (E-mail: r.s.bonser@bham.ac.uk).

J Thorac Cardiovasc Surg 2002;123:943-50

Copyright () 2002 by The American Association for Thoracic Surgery

0022-5223/2002 \$35.00+0 $\quad \mathbf{1 2 / 1 / 1 2 0 3 3 3}$ doi:10.1067/mtc. 2002.120333
Objectives: Although retrograde cerebral perfusion has become a popular adjunctive technique and may improve cerebral ischemic tolerance during hypothermic circulatory arrest, direct cerebral metabolic benefit has yet to be demonstrated in human subjects. We investigated the post-arrest metabolic phenomena with and without retrograde cerebral perfusion in patients.

Methods: In a prospective randomized trial, 42 patients undergoing aortic surgery requiring hypothermic circulatory arrest were allocated to receive hypothermic circulatory arrest alone $(n=21)$ or hypothermic circulatory arrest with additional retrograde cerebral perfusion $(n=21)$. Circulatory arrest was commenced at $15^{\circ} \mathrm{C}$, and retrograde perfusion was instituted through the superior vena cava at a maximum jugular bulb pressure of $25 \mathrm{~mm} \mathrm{Hg}$. Transcranial, paired, repeated samples of the arterial and jugular bulb blood were analyzed for oxygen and glucose. Velocity in the right middle cerebral artery was also measured simultaneously.

Results: There were $3(7.1 \%)$ deaths and $3(7.1 \%)$ episodes of neurologic deficit. Mean bypass and circulatory arrest duration (in minutes) were similar between groups $(P=.4$ and .14$)$. The mean retrograde perfusion duration was 23 minutes. Post-arrest nasopharyngeal temperature was similar $\left(15.3^{\circ} \mathrm{C}\right.$ vs $\left.15.3^{\circ} \mathrm{C}\right)$. Retrograde perfusion did not affect post-arrest oxygen extraction, glucose extraction, or jugular bulb $\mathrm{Po}_{2}$. There was no immediate lactate release immediately after hypothermic circulatory arrest.

Conclusions: Retrograde cerebral perfusion did not influence immediate post-arrest nasopharyngeal temperature or cerebral metabolic recovery. The low jugular bulb $\mathrm{PO}_{2}$ suggests equivalent ischemia. These findings cast doubt on the effectiveness of retrograde cerebral perfusion as a metabolic adjunct to hypothermic circulatory arrest.

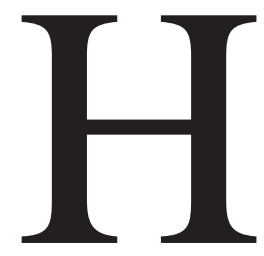

ypothermic circulatory arrest (HCA) is a well-established method to confer cerebral protection during operations involving the aortic arch. Protection of the brain during ischemic arrest is obtained by reducing the temperature, thereby inhibiting metabolic activity. This strategy, however, sets time constraints on the operation and is still associated with significant neurologic morbidity. During the hypothermic arrest period, brain metabolism is not completely halted but continues in an ischemic environment. This exposes the brain to hypoxia, hypercapnia, acidosis, ${ }^{1}$ and elevated levels of excitotoxins ${ }^{2,3}$ that may cause neu- 
TABLE 1. Comparison of demographic, pathologic, and operative variables

\begin{tabular}{lccc}
\hline & HCA group & RCP group & $\boldsymbol{P}$ value \\
\hline No. & 21 & 21 & \\
Age, y (range) & $58(30-70)$ & $63(23-84)$ & \\
Male sex & $12 / 21$ & $12 / 21$ & \\
Pathology & & & \\
$\quad$ Degenerative aneurysm & 15 & 14 & \\
Chronic type A dissection & 1 & 2 & \\
Acute type A dissection & 3 & 2 & \\
Marfan syndrome & 0 & 2 & \\
Congenital aortic stenosis & 0 & 1 & \\
$\quad+$ aneurysm & & & \\
Syphilitic aneurysm & 1 & 0 & \\
Ectodermal dysplasia & 1 & 0 & \\
Total & 21 & 21 & \\
Redo procedures & 0 & 4 & \\
Concomitant CABG & 3 & 0 & \\
Concomitant MVR & 0 & 1 & \\
Extent of resection & & & \\
Ascending aorta \pm root & 13 & 13 & \\
Hemiarch \pm root & 5 & 5 & \\
Total arch \pm root & 3 & 3 & \\
Cardiopulmonary bypass, & $145(24.3)$ & $153(35.7)$ & .401 \\
$\quad$ min (SD) & & & \\
Initial femoral cannulation & $9 / 21$ & $10 / 21$ & \\
Cooling period, min (SD) & $58.5(14.6)$ & $89.0(40)$ & .02 \\
Cardiac ischemic period, & $96.4(28.0)$ & $110.1(39)$ & .2 \\
$\quad$ min (SD) & & & \\
HCA duration, min (SD) & $32(9.0)$ & $27(12.3)$ & .14 \\
RCP duration, min (SD) & - & $23(9.6)$ & \\
\hline
\end{tabular}

$C A B G$, Coronary artery bypass grafting; $M V R$, mitral valve replacement.

ronal apoptosis and necrosis. Retrospective studies have shown that $\mathrm{HCA}$ at a temperature of $15^{\circ} \mathrm{C}$ lasting more than 45 minutes is associated with an increased risk of stroke. ${ }^{4}$ However, a substantial incidence of stroke ${ }^{5}$ and neuropsychometric deficit ${ }^{6,7}$ has also been reported for shorter periods of HCA.

Retrograde cerebral perfusion (RCP) through the superior vena cava during the HCA period has been introduced in an attempt to improve cerebral protection during this vulnerable period. It has been proposed that RCP may increase cerebral ischemic tolerance and prolong the clinically safe duration of circulatory arrest by providing metabolic support, catabolite removal, and preventing brain rewarming during the arrest period. ${ }^{8}$ In addition, RCP may also provide cerebral protection by means of washout of gaseous and particulate emboli without the need for blood to pass through the brain. ${ }^{9}$

In human subjects, studies of cerebral metabolism have been used to investigate the adequacy of clinical cardiopulmonary bypass strategies. ${ }^{10-12}$ These studies have examined measures of cerebral blood flow and oxygen extraction as surrogate indices of cerebral metabolic activity. Further studies have demonstrated deranged cerebral metabolism after HCA, comprising increased transcranial oxygen ex- traction and apparently increased cerebral blood flow..$^{13,14}$ These changes have been interpreted as a metabolic response of the brain to an ischemic insult. Previous human studies have demonstrated a negative linear correlation between cerebral oxygenation and duration of circulatory arrest, ${ }^{15}$ and canine experiments have shown that this cerebral deoxygenation can be attenuated by the use of RCP. ${ }^{16} \mathrm{We}$ hypothesized that if RCP provides metabolic support during circulatory arrest in human subjects, this would be reflected by an attenuation of the post-HCA metabolic derangement.

The aims of this study were therefore to investigate cerebral metabolism immediately after HCA and to investigate the effect of RCP on these changes.

\section{Methods \\ Study Population}

Forty-two consecutive patients (24 male patients) undergoing operations of the aorta requiring HCA were recruited. Patients were randomized to the use of HCA alone or RCP during HCA (HCA plus RCP) by means of a minimization technique ${ }^{17}$ with stratification according to age and the proposed extent of aortic replacement, thus anticipating the likely duration of HCA. Patient details are summarized in Table 1.

The study was approved by the institutional ethics committee, and written informed consent was obtained from all patients before the study.

\section{Anesthetic and Perfusion Techniques}

Anesthesia was induced with etomidate, fentanyl, and pancuronium and maintained with a standard regimen of intravenous propofol and alfentanil. All patients were cannulated with a retrograde jugular bulb catheter, with placement confirmed by means of a postoperative skull radiograph. Cardiopulmonary bypass was instituted with a nonpulsatile roller pump, a membrane oxygenator, and a $40-\mu \mathrm{m}$ arterial line filter with a flow rate of 2.4 $\mathrm{L} \cdot \min ^{-1} \cdot \mathrm{m}^{-2}$. The blood pressure was maintained at a mean of 50 to $55 \mathrm{~mm} \mathrm{Hg}$ with $\alpha$-agonists or glycerine trinitrate as appropriate. Acid-base balance was maintained with an alpha-stat strategy. Patient temperature was monitored by nasopharyngeal and esophageal thermistor probes. Core cooling and rewarming with cardiopulmonary bypass was performed with a water/blood temperature gradient of no more than $10^{\circ} \mathrm{C}$. Topical head cooling with ice was used in all patients before and during the arrest period. In the first 16 patients, myocardial protection was afforded by means of intermittent antegrade cold crystalloid cardioplegia. Cold antegrade blood cardioplegia was used in the remaining patients. During cooling, the ascending aorta was crossclamped, allowing proximal aortic reconstruction. Approximately 20 minutes before HCA, mannitol at $1 \mathrm{~g} / \mathrm{kg}$ and dexamethasone at $100 \mathrm{mg}$ were administered intravenously. Thiopentone was not used. Circulatory arrest was instituted at $15^{\circ} \mathrm{C}$ after repositioning of the patients in a head-down tilt. After release of the aortic crossclamp and initial evacuation of blood from the operating field, arch repair was undertaken under HCA or HCA plus RCP conditions according to the randomization.

In patients randomized to HCA plus RCP, perfusion through the superior vena cava was commenced, and flows were adjusted 
to maintain a jugular bulb pressure of $25 \mathrm{~mm} \mathrm{Hg}$. This provided blood flows of between 300 and $600 \mathrm{~mL} / \mathrm{min}$. During RCP, drainage from the lower body was obstructed by clamping of the inferior vena cava cannula.

After completion of arch repair, antegrade perfusion was recommenced by re-siting the arterial cannula into the arch graft. This was preceded by rigorous deairing procedures, including flooding the operative field with $4^{\circ} \mathrm{C}$ Ringer solution.

Before and after HCA, serum glucose was estimated at 10minute intervals. A blood glucose level of greater than $15 \mathrm{mmol} / \mathrm{L}$ prompted commencement of an intravenous infusion of shortacting insulin.

\section{Cerebral, Hemodynamic, and Metabolic Data}

Transcranial Doppler scan monitoring of the right middle cerebral artery velocity was performed with a SciMed PCDOP 842 device (SciMed, Bristol, United Kingdom). Traces were recorded onto videotape and analyzed offline.

Paired arterial and jugular bulb venous samples were drawn from the arterial and retrograde jugular bulb cannulas, respectively, taking care to avoid artifacts caused by rapid withdrawal. Blood gas samples were analyzed on a NOVASTAT Profile Ultra blood gas monitor (Nova Biomedical Corporation, Waltham, Mass). Blood $\mathrm{pH}, \mathrm{PCO}_{2}, \mathrm{Po}_{2}$, oxygen saturation, oxygen content, and glucose and lactate concentrations were determined. Data are reported immediately before HCA and 1 minute after recommencing full antegrade perfusion.

During RCP, paired transcranial samples were drawn from the (afferent) jugular venous bulb line and from the (effluent) common carotid artery by means of a hand-held, long, soft cannula and similarly analyzed. These data were compared with data obtained from contemporaneous afferent blood samples drawn from the jugular bulb line.

\section{Data Handling and Statistical Treatment}

Data were analyzed by using a commercial statistical software package (SPSS version 7.5, SPSS, Inc, Chicago, Ill) on an IBMcompatible personal computer (IBM Corp, Armonk, NY). Statistical significance testing was performed by means of unpaired Student $t$ tests and analysis of variance.

\section{Results}

The mean age, extent of resection, and bypass and circulatory arrest durations were similar, with no significant statistical difference between the HCA and RCP groups (Table 1 ). The duration of cooling was longer in the RCP group.

There were 3 deaths caused by myocardial failure, 2 in the RCP group and 1 in the HCA group (overall mortality was $7.1 \%$ ). The overall incidence of neurologic deficit was $3(7.1 \%)$ of 42 patients, including 1 permanent neurologic deficit (unilateral sensory loss in the trigeminal nerve distribution) in the HCA group and 2 transient deficits (obtundation) in the RCP group.

Arterial $\mathrm{pH}, \mathrm{PO}_{2}, \mathrm{PCO}_{2}$, glucose concentrations, and hematocrit levels before the onset of HCA were similar in the 2 groups (Table 2).
TABLE 2. Arterial perfusion characteristics

\begin{tabular}{|c|c|c|c|}
\hline & $\begin{array}{c}\text { HCA } \\
(\text { mean } \pm \text { SD) }\end{array}$ & $\begin{array}{c}\text { HCA + RCP } \\
\text { (mean } \pm \text { SD) }\end{array}$ & $P$ value \\
\hline \multicolumn{4}{|l|}{ Before HCA } \\
\hline $\mathrm{pH}$ & $7.6 \pm 0.3$ & $7.7 \pm 0.4$ & .36 \\
\hline $\mathrm{PO}_{2}(\mathrm{~mm} \mathrm{Hg})$ & $215 \pm 34$ & $230 \pm 43$ & .22 \\
\hline $\mathrm{PcO}_{2}(\mathrm{~mm} \mathrm{Hg})$ & $14.6 \pm 0.7$ & $15 \pm 0.8$ & .09 \\
\hline Glucose $(\mathrm{mmol} / \mathrm{L})$ & $8.0 \pm 1.5$ & $7.7 \pm 1.9$ & .57 \\
\hline Hematocrit $(\%)$ & $23 \pm 2.1$ & $22 \pm 1.5$ & .08 \\
\hline \multicolumn{4}{|l|}{ After HCA } \\
\hline $\mathrm{pH}$ & $7.6 \pm 0.35$ & $7.7 \pm 0.45$ & .42 \\
\hline $\mathrm{Po}_{2}(\mathrm{~mm} \mathrm{Hg})$ & $190 \pm 53$ & $205 \pm 32$ & .27 \\
\hline $\mathrm{PcO}_{2}(\mathrm{~mm} \mathrm{Hg})$ & $14.7 \pm 0.9$ & $12.6 \pm 1.1$ & $<.01$ \\
\hline Glucose (mmol/L) & $7.2 \pm 1.2$ & $7.6 \pm 1.6$ & .36 \\
\hline Hematocrit (\%) & $19 \pm 1.7$ & $21 \pm 3.2$ & .02 \\
\hline
\end{tabular}

At the onset of HCA, nasopharyngeal temperature, jugular bulb $\mathrm{PO}_{2}$, and cerebral oxygen extraction were similar in the 2 groups (Figures 1 to 4 )

On reestablishment of antegrade perfusion, perfusate conditions were reexamined. There were no significant differences in arterial $\mathrm{pH}, \mathrm{Po}_{2}$, or glucose concentrations before or after $\mathrm{HCA}$ (Table 2). Arterial $\mathrm{PCO}_{2}$ was significantly lower in the post-arrest arterial perfusate in the RCP group, and hematocrit levels were higher.

There was no increase in nasopharyngeal temperature at the end of the circulatory arrest period in either group (Figure 1).

There was significant reduction in the jugular bulb $\mathrm{Po}_{2}$, with associated increases in oxygen extraction and middle cerebral artery velocity after HCA. The magnitude of these changes was comparable when HCA was supplemented by RCP (Figures 2 to 4) Lactate production was not detected immediately after HCA in either group.

During RCP, transcranial paired sampling showed a significant fall of effluent $\mathrm{PO}_{2}, \mathrm{pH}$, and glucose concentration (Table 3$)$. Transcranial oxygen extraction during RCP (3.3 $\mathrm{mL} / \mathrm{dL}$; range, 0.7-6.6 mL/dL) was significantly higher than extraction observed with antegrade perfusion at similar temperature before or after HCA $(P<.01$, Figure 3$)$.

\section{Discussion}

This study demonstrates that HCA is followed by a significant change in cerebral metabolism. This is manifested by a reduced jugular bulb $\mathrm{Po}_{2}$, increased transcranial oxygen extraction, and an increase in middle cerebral artery velocity. These findings indicate that even relatively short and clinically safe periods of HCA are associated with a cerebral ischemic insult, despite temperature suppression of metabolism. In addition, our study demonstrates that RCP does not attenuate the observed changes in cerebral metabolism after HCA, despite a comparable metabolic profile before and after arrest. Moreover, the high transcranial oxygen 


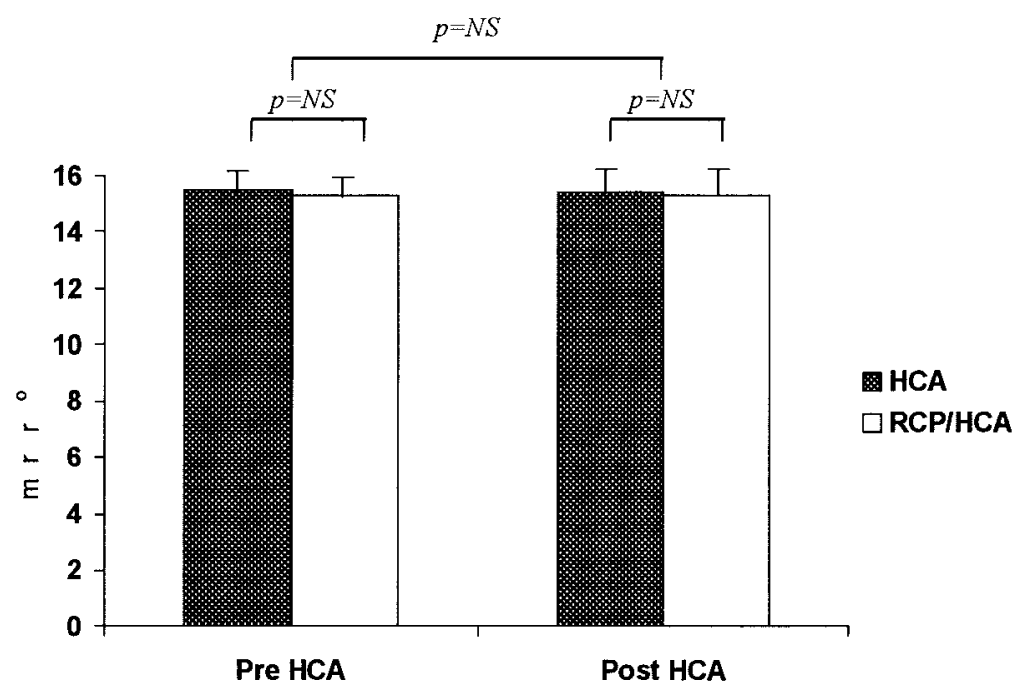

Figure 1. Comparison of nasopharyngeal temperature between groups before and at the end of HCA (in degrees Celsius \pm SEM).

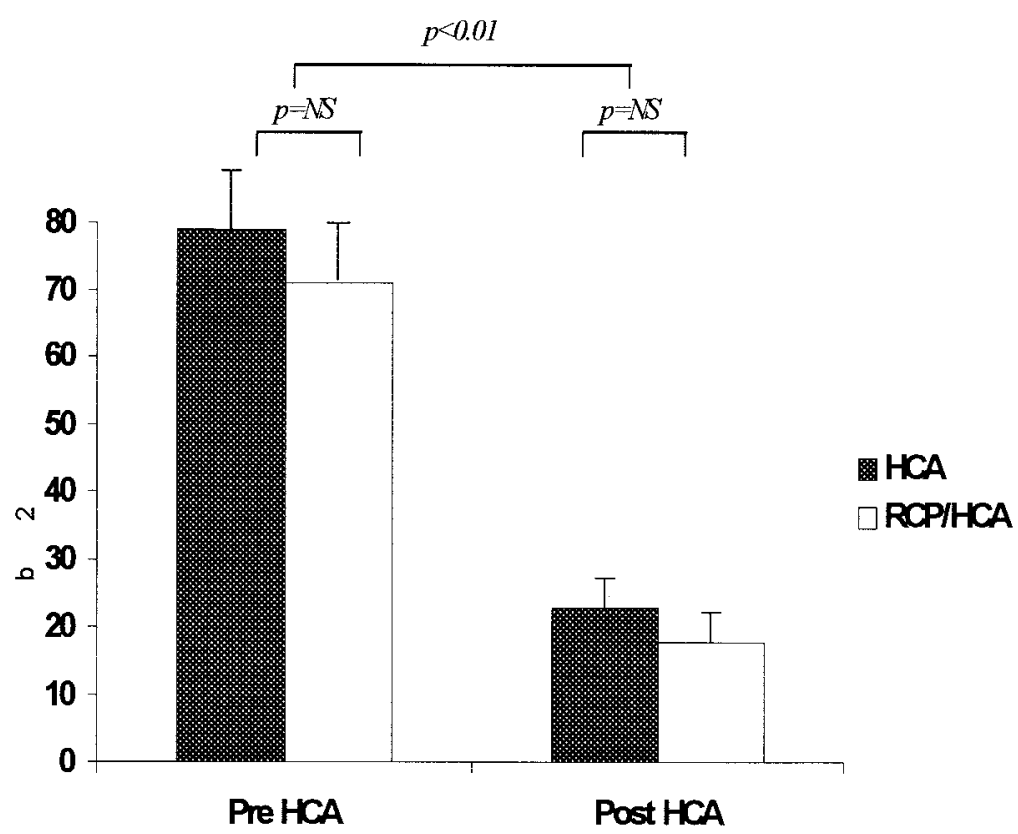

Figure 2. Jugular bulb $\mathrm{Po}_{2}$ in the 2 groups before and immediately after circulatory arrest (in millimeters of mercury \pm SEM).

extraction observed during RCP infers an ongoing metabolic debt. These findings suggest that the ability of RCP to provide metabolic support is limited.

In patients undergoing HCA alone, the use of head packing with ice was not associated with any increase in the nasopharyngeal temperature. These data are consistent with animal studies demonstrating the efficacy of topical head cooling in augmenting protection and preventing rewarming from the environment. ${ }^{18}$ Thus, the proposed role of RCP in maintaining cerebral hypothermia during HCA may be obviated by this simpler technique. However, because perfusate temperature during $\mathrm{RCP}$ was maintained at $15^{\circ} \mathrm{C}$, any additional cooling effect of RCP could not be excluded by this study.

The evidence for cerebral metabolic support by RCP is species dependent. Although RCP is capable of contributing to cerebral metabolism in dogs, ${ }^{19}$ no significant cerebral blood flow or metabolic benefit has been demonstrated in 

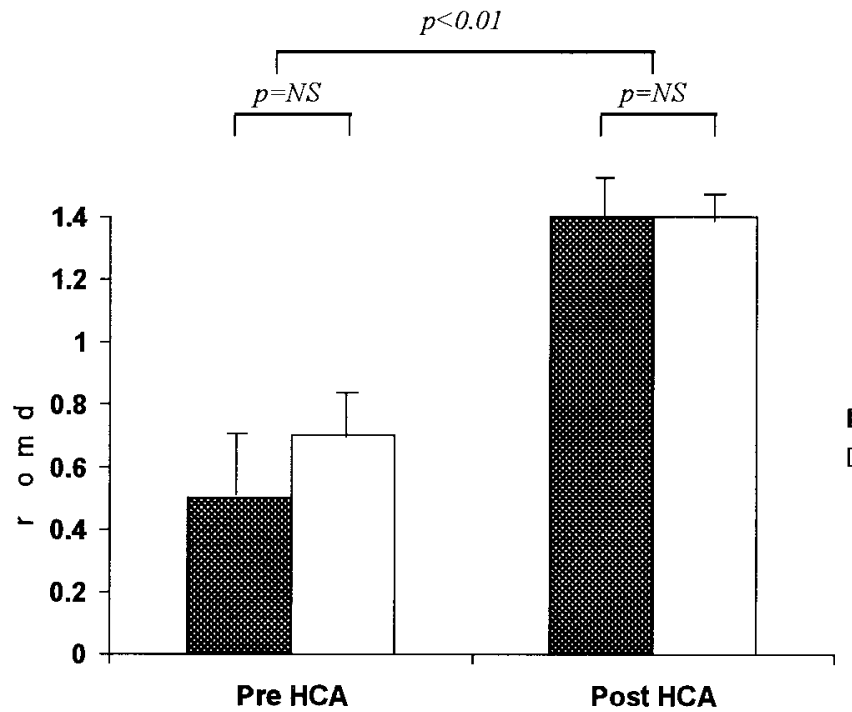

HCA

$\square \mathrm{RCP} / \mathrm{HCA}$

Figure 3. Transcranial oxygen extraction in the 2 groups before and immediately after circulatory arrest (in milliliters per deciliters \pm SEM).

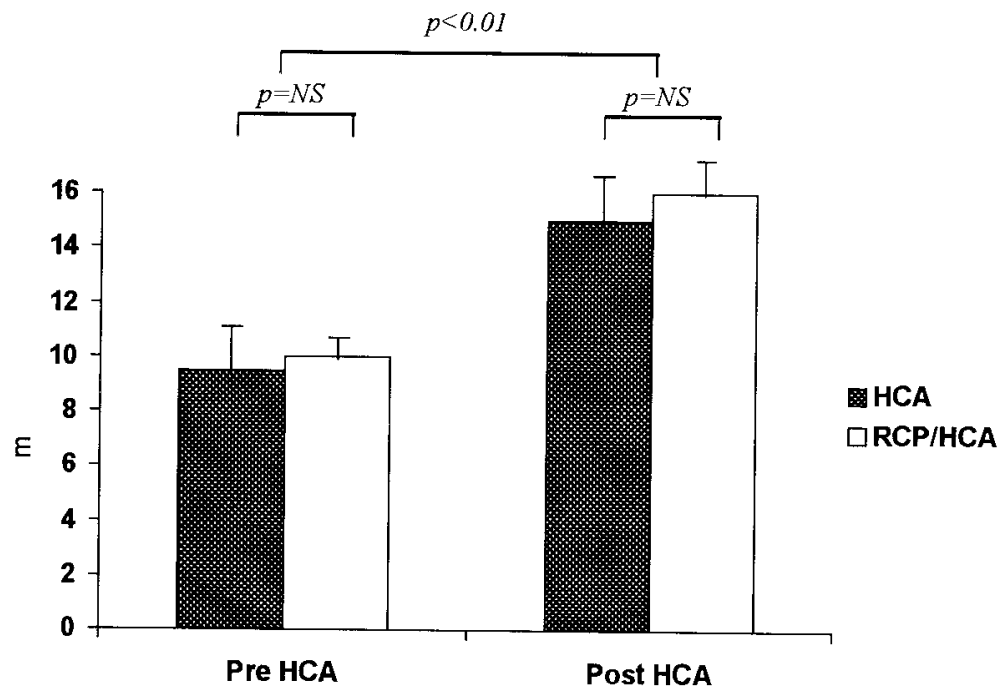

Figure 4. Middle cerebral artery velocity in the 2 groups before and immediately after circulatory arrest (in centimeters per second \pm SEM).

baboons. ${ }^{20}$ Evidence of true cerebral perfusion in human subjects is also limited. We have previously demonstrated, using intraoperative technetium ${ }^{99 \mathrm{~m}} \mathrm{Tc}$ hexamethyl propylene amine oxime $\left({ }^{99 \mathrm{~m}} \mathrm{Tc}-\mathrm{HMPOA}\right.$; Amersham International, Ltd, Little Chalfont, United Kingdom) brain imaging, that cerebral perfusion can occur in patients undergoing $\mathrm{RCP}^{21}$; however, this is variable and cannot be quantified..$^{22}$ This variation could be explained by the fact that delivery of blood to the brain during RCP may be hampered by competent internal jugular vein valves, which have been demonstrated in patients ${ }^{23}$ and cadavers. ${ }^{24}$
Direct estimates of cortical blood flow with laser Doppler scanning after craniotomy in patients undergoing neurosurgical procedures have shown that RCP provides only $10 \%$ of the antegrade baseline cerebral blood flow. ${ }^{25}$ Reversal of the middle cerebral artery flow has also been demonstrated in some patients during RCP, ${ }^{26-28}$ and near infrared spectroscopy studies have suggested that RCP may slow the decrease in the regional cerebral saturation observed in HCA. ${ }^{26}$ These findings could be explained by the presence of venoarterial shunts and arterialization of the cerebral venous blood volume. ${ }^{20}$ 
TABLE 3. Comparison of cerebral inflow and effluent characteristics and transcranial glucose concentration and oxygen extraction during RCP

\begin{tabular}{lccr}
\hline & Afferent blood & Efferent blood & $P$ value \\
\hline $\mathrm{pH}$ & $7.73(7.6-7.9)$ & $7.59(7.5-7.7)$ & $<.01$ \\
$\mathrm{PO}_{2}(\mathrm{~mm} \mathrm{Hg})$ & $226(183-281)$ & $10.9(7.0-17.7)$ & $<.01$ \\
$\mathrm{PCO}_{2}(\mathrm{~mm} \mathrm{Hg})$ & $13.7(10.4-15.9)$ & $17.7(13.1-24.0)$ & $<.01$ \\
$\mathrm{Glucose}(\mathrm{mmol} / \mathrm{L})$ & $7.3(5.3-14.4)$ & $6.9(4.6-12.5)$ & $<.01$ \\
\hline
\end{tabular}

Thus, current data suggest that RCP may provide, at best, little brain perfusion in human subjects. Nevertheless, even a small amount of brain perfusion during HCA could theoretically have an important effect on substrate supply and on the removal of catabolites and excitotoxins..$^{29,30}$ It could be assumed that during HCA, the brain behaves similarly to the ischemic penumbra seen in thromboembolic stroke. This region, unlike the stroke core, does not necrose immediately and may survive for periods of up to 2 to 4 hours while it receives a minimal blood supply $(10-20 \mathrm{~mL} / 100 \mathrm{~g} / \mathrm{min}) .31,32$ In addition, in animal models of stroke, infarct volume can be substantially reduced by lowering the brain temperature and inhibiting excitotoxins. ${ }^{29,33,34}$ Although we have not been able to detect any metabolic effect of RCP, it is possible that benefit might still accrue if RCP is effective in reducing excitotoxin accumulation. In addition, interventions that increase actual reversed flow, such as increased driving pressure or vasodilators, could theoretically exceed the critical threshold above which a meaningful metabolic contribution occurs.

In clinical practice RCP has been found to be a safe technique provided that it is used only at low temperatures and that the venous driving pressure is not excessive. ${ }^{35}$ Comparison of clinical outcomes in patients undergoing $\mathrm{RCP}$ with historical control subjects undergoing HCA alone have suggested an improved stroke and mortality outcome for the RCP group. ${ }^{36,37}$ However, these data could be explained by the fact that patients undergoing HCA alone had more risk factors for stroke, and the patients who received RCP may have benefited from improved anesthetic, surgical, and postoperative techniques compared with the historical series.

A number of small and often uncontrolled series have also failed to demonstrate a clear benefit of RCP on HCA alone. ${ }^{38-40}$ Finally, although the incidence of stroke and mortality increases with HCA duration over 45 minutes, ${ }^{4,41}$ similar findings have been reported with increasing RCP duration in a large multicenter study. ${ }^{42}$

One of the limitations of this study consists of the difficulty in obtaining 2 groups of accurately matched patients because of the great variation in preoperative risk factors, the limited number of patients treated, and the difficulty in estimating intraoperative variables prospectively. To reduce such effects, we adopted a randomization by minimization method. ${ }^{17}$ This achieved comparable ranges for the key factors of age, HCA duration, operation extent, and aortic disease. However, it is still possible that subtle differences between groups introduced an inadvertent and unrecognized bias. For instance, we found that the average cooling period for patients undergoing RCP was significantly longer than for the control group because of a higher number of redo procedures in the RCP group with increased technical complexity of the proximal aortic reconstruction before circulatory arrest. Patients undergoing RCP were also slightly older and had longer myocardial ischemic and bypass times. They also had shorter HCA durations, a lower arterial $\mathrm{PCO}_{2}$, and a higher hematocrit level on reperfusion than control subjects. We believe that these differences would counterbalance each other and were unlikely to affect the results overall. Any such bias is likely to be much less than a comparison with historical control subjects.

Investigating cerebral metabolism in human subjects is a substantial challenge. In animals direct cannulation of the arterial inflow and the cerebral venous sinuses enable direct measurement of flow and metabolic rate. In patients these methods are not possible, and the rate of consumption of oxygen and glucose is conventionally calculated from the product of cerebral blood flow and extraction. Although the technique of measuring cerebral metabolite extraction by blood sampling is widely recognized, the accuracy of techniques measuring cerebral blood flow during cardiopulmonary bypass remains controversial. ${ }^{43,44}$ Currently, there is no universally accepted method of measuring absolute cerebral blood flow during cardiopulmonary bypass, especially in profound hypothermic conditions, during which cerebral blood flow may be a fraction of normal values. In this study we did not attempt to measure absolute cerebral blood flow; rather, we measured changes in cerebral blood flow. Relative cerebral blood flow has been advocated as a better solution given the many assumptions that all available methods have to make. ${ }^{44}$ The oxygen saturation of jugular bulb venous blood is a relevant index of cerebral oxygen extraction at normothermia. During cooling, jugular bulb oxygen saturation rises as a consequence of adequate or superadequate cerebral perfusion and increasing affinity of hemoglobin for oxygen at lower temperatures. We have therefore reported data on jugular bulb $\mathrm{PO}_{2}$ and transcranial 
oxygen extraction to demonstrate the postischemic state of the brain.

The temperature of the brain is a crucial variable. We assessed the nasopharyngeal temperature as the best surrogate measure of brain temperature. The validity of this assumption has been tested in patients undergoing neurosurgery with HCA. ${ }^{45-47}$ Although no surrogate measure precisely correlates with actual brain temperature, especially with rapid cooling or rewarming, nasopharyngeal temperature has the best correlation. Because temperature measurements are reported after a prolonged equilibration period of cooling and after circulatory arrest, we have assumed that the correlation between brain and nasopharyngeal temperature would be close.

The risk of cerebral damage after HCA is related to its duration. In the study population arrest periods were relatively short, and most fell within the clinically acceptable safe duration. Therefore, it is possible that the effect of RCP should be specifically examined in patients with longer HCA periods and that, in such cases, attenuation in the post-HCA phenomena might be observed. However, no beneficial effect was observed in comparisons of the small subgroup of patients with arrest periods of greater than 40 minutes. In addition, if RCP could not attenuate the marked metabolic derangement of a relatively short period of HCA, we believe that it would be unlikely to have improved efficacy over time. However, modifications of RCP that may increase true reverse of brain blood flow can be satisfactorily examined by means of the techniques used.

In this study we did not address the potential of RCP to wash out microscopic or macroscopic emboli or assess the potential for removal of other factors (eg, excitotoxins) that may be a clinically relevant advantage of RCP. However, we did not observe particulate matter in the carotid artery return during RCP and liberally used irrigation with cold saline solution during construction of the arch anastomosis in both groups, allowing aspiration of any debris generated by surgical manipulation.

This study, which was planned as an observational study, has produced a negative finding and may be underpowered. However, animal data have demonstrated significant differences in cerebral oxygenation between HCA and RCP after reperfusion. We assumed that differences in cerebral oxygenation would be reflected in the measurement of the postreperfusion jugular bulb $\mathrm{Po}_{2}$. A priori power analysis on the basis of previous work suggested that a sample size of 21 per group would have a power of 0.8 and an $\alpha$ value of $5 \%$ to detect a $15-\mathrm{mm} \mathrm{Hg}$ difference in postreperfusion jugular bulb $\mathrm{PO}_{2} \cdot{ }^{16}$ Our observations show that after HCA, there is an approximately $60-\mathrm{mm} \mathrm{Hg}$ fall in jugular bulb $\mathrm{PO}_{2}$, and a post hoc analysis suggests that a $30-\mathrm{mm} \mathrm{Hg}$ attenuation of this fall would be detected with 17 patients per group (power, $0.8 ; \alpha, 5 \%$ ). Nevertheless, a smaller attenuation of the postischemic metabolic derangement could be of clinical relevance, and this study would therefore be underpowered to detect this.

In this study RCP did not significantly attenuate the cerebral metabolic sequelae of HCA. RCP may perfuse the brain, but the results suggest that this flow is insufficient to make a major contribution to cerebral oxygenation and that the brain remains ischemic. It is possible that cerebral protection by RCP could be improved if greater actual brain blood flow could be achieved. Despite this, because RCP may improve cerebral protection through other mechanisms, further studies remain necessary to define its role in aortic arch surgery.

We thank the operating department technical staff (K. Parkes and colleagues), anesthetic colleagues, and ITU nursing staff who supported this project.

\section{References}

1. Filgueiras CL, Winsborrow B, Ye J, Scott J, Aronov A, Kozlowski P, et al. A ${ }^{31} \mathrm{P}$-magnetic resonance study of antegrade and retrogade cerebral perfusion during aortic arch surgery in pigs. $J$ Thorac Cardiovasc Surg. 1995;110:55-62.

2. Tseng EE, Brock MV, Kwon CC, Annanata M, Lange MS, Tronoso $\mathrm{JC}$, et al. Increased intra-cerebral excitatory amino acids and nitric oxide after hypothermic circulatory arrest. Ann Thorac Surg. 1999; 67:371-6.

3. Tseng EE, Brock MV, Lange MS, Blue ME, Troncoso JC, Kwon CC, et al. Neuronal nitric oxide synthase inhibition reduces neuronal apoptosis after hypothermic circulatory arrest. Ann Thorac Surg. 1997:64:1639-47.

4. Svensson L, Crawford ES, Hess KR, Coselli JS, Raskin S, Shenaq SA, et al. Deep hypothermia with circulatory arrest. Determinants of stroke and early mortality in 656 patients. J Thorac Cardiovasc Surg. 1993; 106:19-31.

5. Safi HJ, Miller CC 3rd, Reardon MJ, Iliopoulos DC, Letsou GV, Espada R, et al. Operation for acute and chronic aortic dissection: recent outcome with regard to neurologic deficit and early death. Ann Thorac Surg. 1998;66:402-11.

6. Reich D, Uysal S, Sliwinski M, Ergin MA, Kahn RA, Konstadt SN, et al. Neuropsychologic outcome after deep hypothermic circulatory arrest in adults. J Thorac Cardiovasc Surg. 1999;117:156-63.

7. Welz A, Pogarell O, Tatsch K, Schwarz J, Cryssagis K, Reichart B. Surgery of the thoracic aorta using deep hypothermic total circulatory arrest. Are there neurological consequences other than frank cerebral defects? Eur J Cardiothorac Surg. 1997;11:650-6.

8. Wong C, Bonser R. Retrograde cerebral perfusion: clinical and experimental aspects. Perfusion. 1999;14:247-56.

9. Griepp RB, Juvonen T, Griepp EB, McCullough JN, Ergin MA. Is retrograde cerebral perfusion an effective means of neural support during deep hypothermic circulatory arrest? Ann Thorac Surg. 1997; 64:913-6.

10. O'Dwyer C, Prough DS, Johnston WE. Determinants of cerebral perfusion during cardiopulmonary bypass. J Cardiothorac Vasc Anesth. 1996;10:54-65.

11. Hindman BJ, Dexter F, Cutkomp J, Smith T. pH-stat management reduces the cerebral metabolic rate for oxygen during profound hypothermia (17 degrees C). A study during cardiopulmonary bypass in rabbits. Anesthesiology. 1995;82:983-95.

12. Michenfelder JD, Milde JH. The effect of profound levels of hypothermia (below 14 degrees C) on canine cerebral metabolism. J Cereb Blood Flow Metab. 1992;12:877-80.

13. Greeley WJ, Bracey VA, Ungerleider RM, Greibel JA, Kern FH, Boyd $\mathrm{JL}$, et al. Recovery of cerebral metabolism and mitochondrial oxida- 
tion state is delayed after hypothermic circulatory arrest. Circulation. 1991;84:III400-6.

14. Greeley WJ, Ungerleider RM, Smith LR, Reves JG. The effects of deep hypothermic cardiopulmonary bypass and total circulatory arrest on cerebral blood flow in infants and children. $J$ Thorac Cardiovasc Surg. 1989;97:737-45.

15. Ausman JI, McCormick PW, Stewart M, Lewis G, Dujovny M, Balakrishnan G, et al. Cerebral oxygen metabolism during hypothermic circulatory arrest in humans. J Neurosurg. 1993;79:810-5.

16. Usui A, Oohara K, Liu TL, Murase M, Tanaka M, Takeuchi E, et al. Comparative experimental study between retrograde cerebral perfusion and circulatory arrest. J Thorac Cardiovasc Surg. 1994;107: 1228-36.

17. Treasure T, MacRae KD. Minimisation: the platinum standard for trials? Randomisation doesn't guarantee similarity of groups; minimisation does. BMJ. 1998;317:362-3.

18. Midulla PS, Gandsas A, Sadeghi AM, Mezrow CK, Yerlioglu ME, Wang W, et al. Comparison of retrograde cerebral perfusion to antegrade cerebral perfusion and hypothermic circulatory arrest in a chronic porcine model. J Card Surg. 1994;9:560-74.

19. Imamaki M, Koyanagi H, Hashimoto A, Aomi S, Hachida M. Retrograde cerebral perfusion with hypothermic blood provides efficient protection of the brain: a neuropathological study. J Card Surg. 1995; 10:325-33.

20. Boeckxstaens CJ, Flameng WJ. Retrograde cerebral perfusion does not perfuse the brain in nonhuman primates. Ann Thorac Surg. 1995; 60:319-27.

21. Pagano D, Boivin CM, Faroqui MH, Bonser RS. Retrograde perfusion through the superior vena cava perfuses the brain in human beings. J Thorac Cardiovasc Surg. 1996;111:270-2.

22. Pagano D, Boivin CM, Faroqui MH, Bonser RS. Surgery of the thoracic aorta with hypothermic circulatory arrest: experience with retrograde perfusion via the superior vena cava and demonstration of cerebral perfusion. Eur J Cardiothorac Surg. 1996;10:833-8.

23. Tsuchida K, Hashimoto A, Takazawa A, Yamaki F, Koyanagi H. Cerebral death-like conditions after aortic aneurysm surgery using retrograde cerebral perfusion. Cardiovasc Surg. 1993;1:701-3.

24. de Brux JL, Subayi JB, Pegis JD, Pillet J. Retrograde cerebral perfusion: anatomic study of the distribution of blood to the brain. Ann Thorac Surg. 1995;60:1294-8.

25. Lin PJ, Chang CH, Tan PP, Chang CN, Lee ST, Wang CC, et al. Prolonged circulatory arrest in moderate hypothermia with retrograde cerebral perfusion. Is the brain ischemic? Circulation. 1996;94:II16972.

26. Ganzel BL, Edmonds HL Jr, Pank JR, Goldsmith LJ. Neurophysiologic monitoring to assure delivery of retrograde cerebral perfusion. J Thorac Cardiovasc Surg. 1997;113:748-55.

27. Wong C, Bonser R. Retrograde perfusion and true reverse brain blood flow in humans. Eur J Cardiothorac Surg. 2000;17:597-601.

28. Tanoue Y, Tominaga R, Ochiai Y, Fukae K, Morita S, Kawachi Y, et al. Comparative study of retrograde and selective cerebral perfusion with transcranial Doppler. Ann Thorac Surg. 1999;67:672-5.

29. Busto R, Dietrich WD, Globus MY, Valdes I, Scheinberg P, Ginsberg MD. Small differences in intra-ischemic brain temperature critically determine the extent of ischemic neuronal injury. J Cereb Blood Flow Metab. 1987;7:729-38.
30. Usui A, Hotta T, Hiroura M, Murase M, Maeda M, Koyama T, et al. Retrograde cerebral perfusion through a superior vena caval cannula protects the brain. Ann Thorac Surg. 1992;53:47-53.

31. Ashwal S, Tone B, Tian HR, Cole DJ, Pearce WJ. Core and penumbral nitric oxide synthase activity during cerebral ischemia and reperfusion. Stroke. 1998;29:1037-46.

32. Kristian T, Siesjo BK. Calcium in ischemic cell death. Stroke. 1998; 29:705-18

33. Redmond J, Gillinov AM, Zehr KJ, Blue ME, Troncoso JC, Reitz BA, et al. Glutamte excitotoxicity: a mechanism of neurologic injury associated with hypothermic circulatory arrest. $J$ Thorac Cardiovasc Surg. 1994;107:776-86.

34. Siesjo BK, Zhao Q, Pahlmark K, Siesjo P, Katsura K, Folbergrova J. Glutamate, calcium, and free radicals as mediators of ischemic brain damage. Ann Thorac Surg. 1995;59:1316-20.

35. Nojima T, Magara T, Nakjima Y, Waterida S, Onoe M, Sugita T, et al. Optimal perfusion pressure for experimental retrograde cerebral perfusion. J Card Surg. 1994;9:548-59.

36. Coselli JS, LeMaire SA. Experience with retrograde cerebral perfusion during proximal aortic arch surgery in 290 patients. J Card Surg. 1997;12:322-5.

37. Ehrlich M, Fang W, Grabenwoger M, Cartes-Zumelzu F, Wolner E, Havel M. Perioperative risk factors for mortality in patients with acute type A aortic dissection. Circulation. 1998;98:II294-8.

38. Takamoto S, Matsuda T, Harada M, Miyata S, Shimamura Y. Simple hypothermic retrograde cerebral perfusion during aortic arch replacement. A preliminary report on two successful cases. J Thorac Cardiovasc Surg. 1992;104:1106-9.

39. Ueda Y, Miki S, Kusuhara K, Okita Y, Tahata T, Yamanaka K. Surgical treatment of aneurysm or dissection involving the ascending aorta and aortic arch, utilizing circulatory arrest and retrograde cerebral perfusion. J Cardiovasc Surg. 1990;31:553-8.

40. Lin PJ, Chang CH, Tan PP, Wang CC, Chang JP, Liu DW, et al. Protection of the brain by retrograde cerebral perfusion during circulatory arrest. J Thorac Cardiovasc Surg. 1994;108:969-74.

41. Okita Y, Takamoto S, Ando M, Morota T, Yamaki F, Kawashima Y, et al. Predictive factors for postoperative cerebral complications in patients with thoracic aortic aneurysm. Eur J Cardiothorac Surg. 1996; 10:826-32.

42. Usui A, Abe T, Murase M. Early clinical results of retrograde cerebral perfusion for aortic arch operations in Japan. Ann Thorac Surg. 1996;62:94-103.

43. Cook D, Anderson RE, Michenfelder JD, Oliver WC Jr, Orszulak TA, Daly RC, et al. Who's afraid of Kety-Schmidt? Ann Thorac Surg. 1995;60:1156-7.

44. Young WL, Newman MF, Amory D, Reves JG. Cerebral blood flow values during cardiopulmonary bypass: relatively absolute or absolutely relative? Ann Thorac Surg. 1995;59:558-61.

45. Stone JG, Young WL, Smith CR, Solomon RA, Wald A, Ostapkovich $\mathrm{N}$, et al. Do standard monitoring sites reflect true brain temperature when profound hypothermia is rapidly induced and reversed? Anesthesiology. 1995;82:344-51.

46. Hindman B, Dexter F. Estimating brain temperature during hypothermia. Anesthesiology. 1995;82:329-30.

47. Aebert H, Brawanski A, Philipp A, Behr R, Ullrich OW, Keyl C, et al. Deep hypothermia and circulatory arrest for surgery of complex intracranial aneurysms. Eur J Cardiothorac Surg. 1998;13:223-9. 